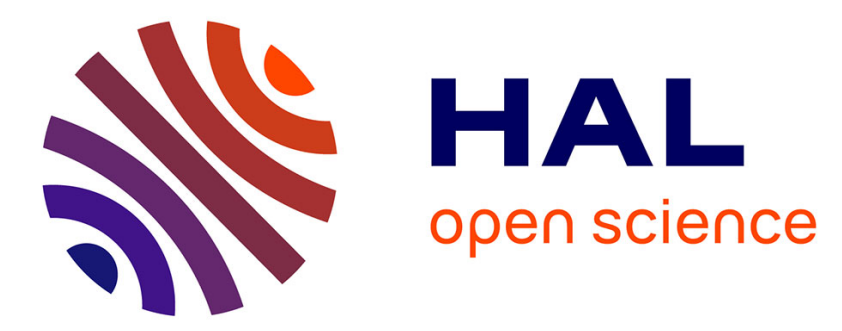

\title{
Backing to Single Carrier in Tera Hertz Communications for Green Considerations
}

Jacques Palicot, Faouzi Bader

\section{To cite this version:}

Jacques Palicot, Faouzi Bader. Backing to Single Carrier in Tera Hertz Communications for Green Considerations. XXXII International Union of Radio Science General Assembly \& Scientific Symposium (URSI), Aug 2017, Montréal, Canada. pp.19 - 26, 10.23919/ursigass.2017.8105038 . hal01705738

\section{HAL Id: hal-01705738 \\ https://hal.science/hal-01705738}

Submitted on 9 Feb 2018

HAL is a multi-disciplinary open access archive for the deposit and dissemination of scientific research documents, whether they are published or not. The documents may come from teaching and research institutions in France or abroad, or from public or private research centers.
L'archive ouverte pluridisciplinaire HAL, est destinée au dépôt et à la diffusion de documents scientifiques de niveau recherche, publiés ou non, émanant des établissements d'enseignement et de recherche français ou étrangers, des laboratoires publics ou privés. 


\title{
Backing to Single Carrier in Tera Hertz Communications for Green Considerations
}

\author{
Jacques Palicot and Faouzi Bader \\ SCEE/IETR - CentraleSupélec, Rennes. \\ 35576 Cesson-Sévigné, Rennes, France. E-mail: firstname.name@centralesupelec.fr
}

\begin{abstract}
It is estimated that the demand for data rate in wireless networks increases by $40 \%$ up to $70 \%$ year upon year. This tremendous growth implies that within the next 10-15 years, the wireless networks may need to deliver as much as several hundreds of times the capacity as compared to the current levels. To reach this Terabit per seconds (Tbps) data rate a very broad bandwidth will be required. That is the main reason why the community is today focused on higher band like Terahertz (THz) band. The definition of an efficient physical layer (PHY-layer) in the considered frequency band is very challenging due to radio frequency impairments and complexity. The purpose of this paper is to provide recent views on the evolution concepts and potential schemes for Tbps wireless communications by backing to the basis of single carrier modulation.
\end{abstract}

\section{Introduction}

Since the 90's, the most predominant communication scheme for broadband wireless communications is the multi-carrier (MC) scheme, more precisely the Orthogonal Frequency Division Multiplexing (OFDM) modulation. This is still the case for the last few years where many actors are studying advanced multi-carriers modulations (FBMC, GFDM, etc.) for fifth generation (5G) communication systems [?]. For systems beyond 5G, the expected date rate will reach Tbps which implies the use of ultra wide bandwidths of several tens of $\mathrm{GHz}$. These bandwidths are not available in the classical bands below $100 \mathrm{GHz}$. This is the main reason why the community is today focusing and exploring on higher bands like Tera hertz $(\mathrm{THz})$ band. Although there are several EU research projects dealing with wireless communications in high frequency bands, their focus is mainly on frequencies below $90 \mathrm{GHz}$. As almost all these projects were accepted within H2020 5GPPP framework, with a focus limited to 5G communication rates rather than beyond $5 \mathrm{G}$ which is the focus of this paper. Moreover, the radio access technology considered is still mainly based on MC modulation. Among the EU projects focusing on 60-90 GHz communications band, we name, the Flex 5 Gware $^{1}$ project, and the mmMAGIC

\footnotetext{
${ }^{1}$ http://www.flex5gware.eu/
}

project $^{2}$. This last is concerned with the development and use of SC schemes for millimeter wave communications.

The main justification for the use and the deployment of multi-carrier communication systems is their adequacy and benefits in frequency selective channels by the possibility of generating and implementing a large number of flat small channels. In fact, in such channel environment, the OFDM modulation translates the Inter Symbol Interference effect in a broadband single carrier (SC) into several flat (eventually attenuated) and very narrow band channels. This was the principal interest for the development of the MC communication scheme concept. Associated with a powerful coding and interleaving schemes, in both frequency and time domains, the well known Coded OFDM (COFDM) achieved very interesting results and has been used as a prevailing PHY layer in many standards. Of course some drawbacks related to OFDM (and MC in general) modulation exists and were quickly identified such as, the Inter Carrier Interference (ICI) effect, and the high Peak to Average Power Ratio (PAPR). Despite these limitations, achieved results by means of real implementations and testing were so successful in high selective terrestrial channels that they did not influenced the OFDM standardization and its worldwide commercial success. In some particular situations such as, satellite transmissions or cellular uplink communication mode in Long Term Evolution Advanced (LTE-A) system, MC modulations have been discarded because of the negative effect of the PAPR phenomena.

Transmission at $60 \mathrm{GHz}$ covers less distance for a given power, mainly due to the increased free space path loss (loss over $1 \mathrm{~m}$ at $60 \mathrm{GHz}$ is $68 \mathrm{~dB}$, which is $21.6 \mathrm{~dB}$ worse than at $5 \mathrm{GHz}$ ) band compounded by propagation losses through materials and human body shadowing (losses from a few $\mathrm{dB}$ to $30 \mathrm{~dB}+)$ [?]. In contrast, oxygen absorption plays a minor role over short range distances even through it peaks at $60 \mathrm{GHz}$. The above $100 \mathrm{GHz}(100-300 \mathrm{GHz})$ band communications is characterized by a higher degree of absorption than in the $60 \mathrm{GHz}$ band, and by a quasi-optical propagation behavior where the received signal is dominated by line of sight (or along a strong indirect path) and reflexions from strong reflecting materials, and the MIMO precoding generates a flat channel at the receiver side [?]. On the other

\footnotetext{
${ }^{2}$ https://5g-mmmagic.eu/
} 
hand, the non line of sight (NLOS) environments losses are too high for reliable communications, and concrete materials cause additional large signal attenuation and can easily create a blockage.

This type of physical communication environment is more conducive for the use of SC modulation scheme. The SC has been proposed in WiFi 802.11ad standard (also named WiGig) [?], and is object to deep researches for millimeter wave communications in [?] for essentially keeping the transceiver complexity and the energy consumption low and affordable for real implementation. Note that with frequencies of order of tens of $\mathrm{GHz}$ bandwidth to reach tbps in beyond $100 \mathrm{GHz}$ band, it seems unrealistic to have analogue to digital converters (ADC) with several bits at a reasonable energy consumption. Therefore, all the signal processing for beamforming and classical signal processing at the receiver side should be revisited taking into account a mix of analog and digital design.

The special characteristics of the associated channels, especially from the mm-Wave frequency bands over $60-90 \mathrm{GHz}$, make SC modulation schemes, unlike the MC scheme, potentially more appropriate for communication systems operating in such high communication bands and beyond. This is what emerged from recent studies in [?] and [?], where SC was described as a promising candidate to provide good coverage even when wider bandwidth transmissions (e.g., > $10 \mathrm{GHz}$ ) are introduced in these high frequency bands. Another extremely important argument in favor of the use of SC modulation, is the Peak-to-Average Power Ratio (PAPR) that will be lower than MC systems, making possible the use of more energy efficient power amplifier for such high frequency ranges. Combined with simpler modulation/demodulation blocks, the global energy consumption will be significantly reduced. We remind, here, that green radio communication is considered as a strong and an unavoidable argument for next generation systems. Therefore, backing to single carrier modulation will help to meet such essential requirement. The rest of this paper is focusing on this last aspect.

\section{WHY we essentially use OFDM modula- tion?}

To well understand the interest of dividing a broad band into a large number of narrow bands, let's have a look on Figure ??. In this Figure, published in [?], depicts a 3D representation of a frequency selective channel. For a given time, the projection in the frequency direction exhibits holes or deep attenuation that are experiencing variations in time domain due to the mobility effects of the transmitter. If the overall band is split in many small bandwidths (see depicted small squares on the $3 \mathrm{D}$ channel representation), we may consider the variation of the channel in each square as flat. Dividing the frequency band in several pieces of small bands to fight the frequency selectivity of the channels is an old idea. One of the pioneer theoretical works is

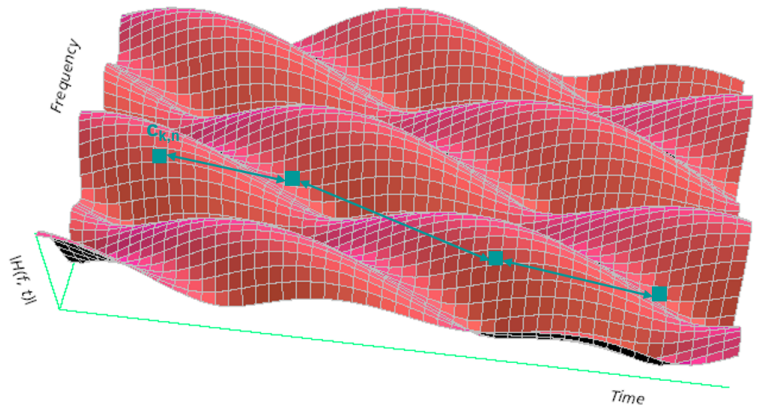

Figure 1. Example of a 3D (Time Frequency Power) varying channel [?]. Each small square could be considered as a flat (eventually attenuated) channel.

that of Collins Radio company in the 60's, where the basic idea consisted in transmitting simultaneously the data on several carrier frequencies with a low bit rate on each. The real implemented system was based on a modem using a two frequency shift keyring modulation (2FSK) scheme over 40 parallel channels. In 1966, the work presented by Chang in [?] allowed to identify and to set the orthogonality conditions in order to optimize the overall used bandwidth. We can consider the Chang's published work as the birthdate of the OFDM modulation, and as a disruptive innovative evolution on radio communication era. Very quickly, engineers identified the synchronization issue, in both time and frequency, as crucial in order to kept the Chang's orthogonality criteria between the different parallel carriers at the receiver side. From the complexity point of view, to realize many modulators (one per each narrow band) in parallel with high level of orthogonality was very challenging. Thanks to the work of Weinstein and Ebert in [?], it was demonstrated that it is possible to replace the parallel modulators bank by a fast Fourier transform (FFT) at both the transmitter and the receiver sides. After this milestone, the scientific community has adopted this major advance and from that time a huge number of researches has been produced in this field. Two others key factors as the advent of very powerful Digital Signal Processors (DSPs) devices with its combination with code schemes associated to the modulation (known as coded OFDM [?]) explained the success of the COFDM in the 90's. In fact, COFDM multicarrier scheme is the key modulation adopted in many wirelesss communication standards as: DAB, ADSL, DVB-T, WiFi, LTE, etc.

\section{PAPR issues for energy efficiency}

\subsection{Green radio-communications}

Few years ago, the environmental-friendly sustainable development was only the concern of ecological organizations. However, sustainable development has become a globally paramount challenge and an aspiration of longterm civilization development of all human beings since the "Resolution 42/187 of the United Nations General Assembly" in December 1987. The Brundtland Commission of 
the United Nations (UN) has defined sustainable development as the one that "meets the needs of the present without compromising the ability of future generations to meet their own needs". From then on, several United Nations' conferences (from Rio de Janeiro-1992 to more recently the COP'21 in Paris, 2015) continually confirmed this important issue, for which one of the most obvious aspects and challenges of sustainable development is the earth climate change and the ever-growing $\mathrm{CO} 2$. Doubtlessly, making Information and communications technology (ICT) equipments and applications "greener" in terms of energy consumption can not only have a tangible positive impact on environment, but can also help telecommunications operators to attain long-term profitability. Moreover, energyefficient communications and networks can help the world to reduce the dependence on fossil fuel, enable on-demand response and fluent energy resources distribution, and ultimately achieve sustainable prosperity around the world. This evolution was recently stated in many papers and conferences. As illustrated in Figure ?? of [?], the long-term evolution road map of next-generation telecommunications systems from $2 \mathrm{G}, 3 \mathrm{G}$ to $4 \mathrm{G} / 5 \mathrm{G}$ is strongly expected to point to the energy-efficiency dominated era from now on.

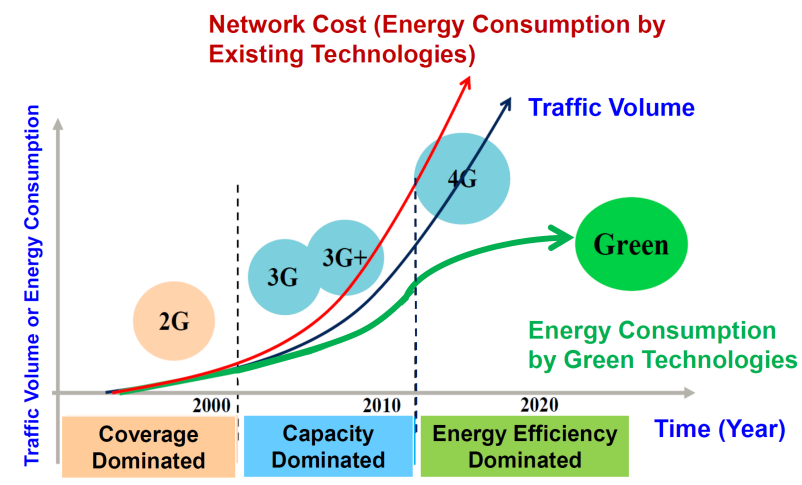

Figure 2. Evolution from coverage- and capacity-driven telecommunications to energy-efficient green radio communications from [?].

\subsection{PAPR considerations}

\subsubsection{Multi-carrier case}

The envelope of a multiplex of modulated signals (for both single-carrier and multi-carrier signals) is not constant. This is always true, for example, for software radio signals like a multiplex of GSM signals (even if each one is actually of constant envelope). The large variations of the multi-carrier transmitted signals lead to a weak power efficiency of the power amplifier and, therefore, intensive energy consumption requiring a growing need for cooling is observed. All the classical multi-carrier systems, as the OFDM, suffer from high power fluctuations. The variations of the signal envelope generate non-linear distortions, when we introduce the OFDM signal into a power amplifier (PA). Considering the graph of Figure ??, about $30 \%$ of the base station power consumption is due to the high power ampli- fier (HPA) and the associated cooling. Depending on in-site implementation technologies this value may reach 50\% [?]. This explains the existence of huge scientific literature on HPA efficiency optimization methods. This last problem may be tackled at different levels [?].

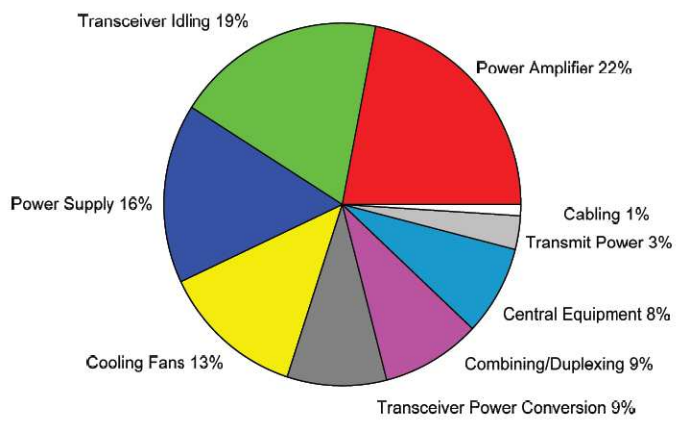

Figure 3. Example of Power consumption sharing at a Base Station [?].

The PAPR is a random variable which has been introduced to measure the power variations of the OFDM or any MC signal. A lot of researches have been conducted in order to reduce the PAPR effects and to analyze its probability distribution. A huge number of studies and developed techniques exist for the PAPR reduction that cannot be discussed in this paper. The reader may refer to many overview papers or books as [?], [?], [?], and to the recent work using Tone Reservation method in [?].

Another way to tackle the PAPR problem is to try to find a new multi-carrier scheme with low PAPR by construction, which means to define a new waveform with low PAPR. In [?] and [?], we proposed an optimization problem on the waveform in order to have an MC system with low PAPR. In [?] we solved this optimization problem and we obtained the following major result that is, no better PAPR compared to OFDM, is possible, without reducing the temporal support of the analyzed waveform. In [?], we proved that all the proposed enhanced multi-carrier waveforms for $5 \mathrm{G}$, like $\mathrm{FBMC}^{3}, \mathrm{UFMC}^{4}$, and $\mathrm{GFDM}^{5}$ [?] are all identical or worse than OFDM in terms of PAPR because they not fulfill the condition of having a temporal support smaller than the symbol period.

\subsubsection{Single carrier case}

Recent conducted researches for millimeter-wave communications [?] focused on several SC modulations like, the Continuous Phase Modulated Single-Carrier Frequency Division Multiple Access (CPM SC-FDMA) which is a generalization of SC-FDMA using samples of a Continuous Phase Modulation (CPM) signal as generalized coded modulation input symbols [?]. The scheme can provide a low PAPR signal with very low side lobes, provided the CPM parameters like over-sampling factor and sub-carrier mapping have to be suitably selected. It is shown that a good

\footnotetext{
${ }^{3}$ Filter bank Multi-Carrier

${ }^{4}$ Universal Filtered multi-Carrier

${ }^{5}$ Generalized Frequency Division Multicarrier
} 
PAPR versus spectral efficiency trade-off is obtained with an oversampling factor of two together with Interleaved Frequency Division Multiple Access (IFDMA) mapping. An other scheme is the Constrained Envelope Continuous Phase Modulation (ceCPM-SC) Constrained envelope which is a true single carrier scheme generalizing CPM by allowing controlled small envelope variations [?]. Pure single-carrier waveforms are relatively robust to channel time selectivity compared to multi-carrier waveforms. The reason is that single-carrier waveforms have shorter symbol durations that are subject to less channel variations across time. In order to reach the magnitude of Tbps, the considered SC modulation should have a high spectrum efficiency. In other words, constant envelope modulations like CPM could be limited due its low spectrum efficiency. As a consequence, modulation having high spectrum efficiency means many symbols in the I/Q plan which, in turn, implies a non-negligible PAPR (depending on the used filtering function) effect. In [?] we proved that the PAPR increases when the roll-off factor oh the Nyquist filter decreases. To decrease this PAPR, some mitigation techniques studied in the multi-carrier context could be adapted and applied in beyond $100 \mathrm{GHz}$ band, i.e., Modified Tone Reservation technique in [?] could be studied.

\section{Conclusion}

Single carrier modulations are gaining more and more interest than past few years. The fact that beyond $5 \mathrm{G}$ communications targeting wireless applications with Tbps data rate in beyond $100 \mathrm{GHz}$ band, characterized by a higher degree of absorption and by a quasi-optical propagation behavior with line of sight received signal, is very conducive for the use of SC modulations due to the previously mentioned green considerations. Nonetheless, more deep researches have to be conducted to develop advanced signal processing techniques to increase the SC modulation capacity and phase noise robustness, and to reduce the PAPR and the out of band emission.

\section{References}

[1] "New Waveforms for 5G Networks", IEEE Communications Magazine, vol 54, $\mathrm{n}^{\circ}$ 11, November 2016, pp. 64-112.

[2] Thomas Nitsche, Carlos Cordeiro, Adriana B. Flores, Edward W. Knightly, Eldad Perahia, and Joerg C. Widmer, "IEEE 802.11ad: directional $60 \mathrm{GHz}$ communication for multi-Gigabit-per-second Wi-Fi", IEEE Communications Magazine, vol. 15, issue 12, 2014, pp. 132-141.

[3] S. Salous, Stuart M. Feeney, X. Raimundo, and Adnan A. Cheema, "Wideband MIMO Channel Sounder for Radio Measurements in the $60 \mathrm{GHz}$ Band", IEEE Transactions on Wireless Communications, vol. 15, $\mathrm{n}^{o} 4$, April 2016, pp. 2825-2832.

[4] The EU project-mmMAGIC, code: H2020-ICT-671650. Technical report D4.1: "Preliminary radio Interface concepts for mm-wave mobile communications," June 2016. Available at: https://5g-mmmagic.eu/. [Accessed: 31-January2017].
[5] A. Ghosh et al, "Millimeter-wave enhanced local area systems: A high-data-rate approach for future wireless networks," IEEE Journal on Selected Areas in Communications, vol. 32, $\mathrm{n}^{\circ}$ 6, pp. 1152-1163, June 2014.

[6] DOCOMO, "5G Radio Access: Requirements, Concepts and Technologies," 5G White Paper, July 2014.

[7] J. H. Stott, "The How and Why of COFDM," EBU Technical Review, Winter 1998.

[8] R. W. Chang, "Synthesis of Band Limited Orthogonal Signals for Multichannels Data Transmission," Bell Syst Technical J, vol. 45, December 1966, pp. 1775-1796.

[9] S. Weinstein, P. Ebert, "Data Transmission by Frequency Division Multiplexing Using the Discrete Fourier Transform," IEEE Trans. Comm. Tech, vol 19, $\mathrm{n}^{o}$ 11, October 1971, pp. 628-634, doi: 10.1002/2015RS005822.

[10] J. Palicot, H. Zhang, C. Moy, "On the Road Towards Green Radio," Radio Science Bulletin, ${ }^{o}$ 347, December 2013, pp. 40-56.

[11] M. Alard, R. Lassalle, "Principles of Modulation and Channel Coding for Digital Broadcasting for Mobile Receivers," EBU Review Technical, August 1987, pp. 168-190.

[12] Y. Louet, J. Palicot, "A classification of Methods for Efficient Power Amplification of Signals," Annals of Telecom, vol. 63, $\mathrm{n}^{\circ}$ 7-8, August 2008, pp. 351-368.

[13] W. H. Doherty, "A New High Efficiency, Power Amplifier for Modulated Waves," Proceedings of the IRE, vol. 24, $\mathrm{n}^{\circ}$ 9, 1936.

[14] S.H. Han, J. H. Lee, "An Overview of Peak-to-Average Power Ratio Reduction Techniques for Multi-Carrier Transmission," IEEE Transactions on Wireless Communications, vol. 12, no 7-8, April 2005, pp. 56-65.

[15] H. B. G. Wunder, R. Fischer, S. Litsyn, "The PAPR Problem in OFDM Transmission: New Directions for a Long-Lasting P," IEEE Signal Processing Magazine, vol. 63, nº 7-8, October 2013, pp. 130-140.

[16] M. L. Diallo, M. Chafii, J. Palicot, F. Bader, "Modified Tone Reservation for PAPR Reduction in OFDM Systems," EUSIPCO 2016, Budapest, Hungary, September 2016.

[17] M. Chafii, J. Palicot, R. Gribonval, F. Bader, "Closed-form Approximations of the Peak-to-Average Power Ratio Distribution for Multi-carrier Modulation and their Applications," EURASIP Journal on Advances in Signal Processing , 2014 (1) (2014) pp. 1-13.

[18] M. Chafii, J. Palicot, R. Gribonval, F. Bader, "A Necessary Condition for Waveforms With Better PAPR Than OFDM," IEEE Transactions on Communications, vol. 64, $\mathrm{n}^{\circ} 8$, August 2016, pp. 3395-3405.

[19] J. Palicot, Y. Louet, "Power Ratio definitions and analysis in single carrier modulations," EUSIPCO 2005, Antalya, Turkey, September 2005. 